Long, D. and Arroyo, P. (2018). "Language, Moods, and Improving Project Performance" In: Proc. 26

Annual Conference of the International. Group for Lean Construction (IGLC), González, V.A. (ed.), Chennai, India, pp. 495-504. DOI: https://doi.org/10.24928/2018/0541. Available at: www.iglc.net.

\title{
LANGUAGE, MOODS, AND IMPROVING PROJECT PERFORMANCE
}

\author{
David Long ${ }^{1}$ and Paz Arroyo ${ }^{2}$
}

\begin{abstract}
Compared to other industries, the construction sector has lagged in improving productivity. Effective performance, of which productivity is an indicator, is facilitated by conversation that clearly identifies necessary steps to achieve common goals. The type of language used in productive conversation can be referred to as the language of action; similarly, the term "linguistic action" denotes a domain of effective speech to facilitate action. However, even when linguistic action is employed, teams may struggle to communicate effectively when the speech or moods of individuals, or the environments in which they are operating, are not conducive to either productive action or dialogue. This paper proposes direct relationships between linguistic action, positive moods and team performance. It observes that the ability to recognize and influence moods suggests that team performance can be improved by fostering positive moods in the work environment. Two research questions are explored: 1) What research has connected Linguistic Action and mood to increased performance? 2) What are potential new opportunities for connecting Linguistic Action and mood to performance on projects?
\end{abstract}

\section{KEYWORDS}

Linguistic Action, Productivity, Performance, Language Action, Learning Behaviors, Lean, Moods.

\section{INTRODUCTION}

The lean construction community has long recognized low productivity issues in the global construction industry. Construction related spending accounts for $13 \%$ of the world's GDP, yet the sector's annual productivity growth has increased only $1 \%$ per year for the last 20 years (McKinsey report 2017).Although this report provides a healthy dose of cautionary disclaimers it outlines seven ways to tackle ten root causes of poor productivity. The adoption of lean principles in project management has been shown to increase productivity, primarily as a result of applying The Last Planner ${ }^{\circledR}$ System (LPS), a commitment-based production process control method. LPS recognizes the positive effects of making and securing reliable promises, and as a management philosophy streamlines decision-making and production processes. Ballard and Howell (1994)

Principal, David Long Consulting CA, USA, longd2@me.com

Adjunct Assistant Professor, Universidad Católica de Chile parroyo@ing.puc.cl and Senior Coach, LeanProject Consulting CA, USA, parroyo@leanproject.com 
illustrated the connection between commitments kept on projects, measured by "Percent Planned Complete" (PPC) in LPS, and increased productivity. Macomber and Howell (2003) connected both the linguistic action perspective (LAP), and research from Flores (2012), to improved project management. Flores (2012) identified the five "speech acts" (Fig. 1) of effective conversation (Declare, Assess, Request, Offer, Promise and Assert) and how they can be applied in the work environment to frame discussions as "conversations for action." The LPS uses the speech act of "promise" to establish commitments, thus reducing variability and increasing productivity. The direct connection between increased fulfilment of commitments, as measured by the Percent Plan Complete (PPC) in the Last Planner System, and increased productivity was shown by Ballard and Howell (1994) and again by Liu et al. (2010). Understanding commitments as promises, one of the speech acts in Flores (2012), establishes the direct connection between linguistic action and increased productivity.

Flores, G.P. (2016) further advanced the work of Flores, F. (2012) by observing the connection between moods and learning; moods that are unproductive or moods that are conducive to learning are identified, and the nature of mood and learning, as well as their connection to collaborative team performance, is explored. Commitment (promise) in the function of the LPS exemplifies how Flores's "speech acts" can be used to improve performance on construction projects. Although the remaining four speech acts are mentioned in the literature, there is not much discussion about how to explicitly apply them to improve project performance. Even less has been said to connect project performance and mood, and there is no discussion of the methods by which moods can be improved to positively affect construction project outcomes. The literature on speech acts from the linguistic action perspective in construction reflects a variety of authors' attention to the relationship between performance, the use of linguistic action and the potential effect of mood on projects.

\section{RESEARCH QUESTION AND METHOD}

The research questions are: 1) What research has connected Linguistic Action and Lean to increased project performance? 2) What are potential new opportunities for connecting Linguistic Action and mood to performance on projects?

This paper shows the results of a review of previous research studies exploring "linguistic action" in the lean construction literature; past IGLC papers were given particular attention in the analysis.

\section{LANGUAGE ACTION}

In his book Conversations for Action and Collected Essays (2012), Fernando Flores writes about using "action language" to in still a culture of commitment in working relationships. Expanding on the linguistic action work of Austin, J. (1975) and Searle J. (1969), Flores defines six basic speech acts: declaration, request, promise, offer, assessment, and assertion (Table 1). Understanding the nuances of each speech act can explain dysfunction in communication and shed light on action outcomes. In related research, Macomber and Howell (2003) borrowing from Flores, F. (2012), observed that 
projects are a network of commitments, while (Ballard, G. and Howell, G., 1994) used percent planned complete (PPC) to measure and illustrate the direct relationship between commitments made on projects and improved productivity. Beyond being a "network of commitments," a project should also be considered as a "network of conversations" built on all five speech acts defined by (Flores 2012) to further improve productivity.

Table 1: Speech Acts and Actions

\begin{tabular}{lll}
\hline $\begin{array}{l}\text { Act } \\
\text { Declare } \\
\text { Assess }\end{array}$ & $\begin{array}{l}\text { What it Does } \\
\text { Open a new world for action } \\
\text { Open new possibility or prepare for action }\end{array}$ & $\begin{array}{l}\text { Elements } \\
\text { Infers authority } \\
\text { Futuristic, grounded, or } \\
\text { ungrounded }\end{array}$ \\
Offer & $\begin{array}{l}\text { The speaker is asking a potential performer } \\
\text { for action around a concern } \\
\text { Performer promises to care about something } \\
\text { background of obviousness, } \\
\text { time } \\
\text { about }\end{array}$ & $\begin{array}{l}\text { Same as request } \\
\text { Commit self/enterprise/team to bring a new }\end{array}$ \\
Assert & $\begin{array}{l}\text { Condition of Satisfaction } \\
\text { Speaker reports facts and is prepared to offer } \\
\text { evidence }\end{array}$ & Same as request \\
\hline
\end{tabular}

\section{MOODS}

In Flores, G.P. (2016.) Learning to Learn and the Navigation of Moods, Gloria Flores makes the distinction between moods that are either unproductive or conducive to learning. In addition, moods affect the possibilities that people see for their future. She observes that moods are contagious and invisible and that moods can be cultivated. She also states that moods are not emotions, that moods are in the background and are not about a particular event. Humans are historical beings whose possibilities are shaped by historical occurrences. She states that moods are triggered by assessments that are usually automatic.

She presents unproductive moods, and examples of assessments people make when falling into these moods. Here we present these moods with examples of assessments we have heard and observed in construction projects:

- Resignation: There is nothing I can do to make this project better; even if I work hard, these subcontractors will not do their part.

- Arrogance: I have experience in this type of project, and I know what I have to do. I do not want to waste my time planning.

- Confusion: I don't understand what is going on. No one is letting me know what I should do. I am just going to keep myself busy.

- Frustration: I have tried to change this project to be a more effective and productive team, but everyone goes back to work in the same old way. 
- Impatience: There is no value in planning. This is a waste of everyone's time. We should be working on site!

- Distrust: I do not trust these subs. These guys are just unreliable. I cannot ask for their help. We will need to add more contingency to this job.

- Overwhelmed: There is so much to design in this project and people are not even talking to each other! We will make mistakes for sure.

- Powerless: I don't like how things are, but there is nothing I can do to change the system.

She further presents moods conducive to learning. In this paper we are presenting these moods with examples of assessments that we have heard or observed in construction practice that lead to productive conversations.

- Wonder: I do not understand the whole design but I wonder if there is a better way to create the value for the client.

- Serenity/Acceptance: The future is uncertain, there will be surprises, but our team will be able to get through it.

- Ambition: I see opportunities to improve and I am willing to convince others to try them. I am committed to taking action and lead the way.

- Resolution: I see opportunities to implement lean in this project and I will take action right now.

- Confidence: We have been successful in complex projects in the past and I know we will be able to do it again.

- Trust: I am confident that the team will deliver what we need to succeed in this project.

With regard to navigating moods, Gloria Flores (2016) observes: "we can not avoid falling into unproductive moods, but we can learn not to be trapped by them". This "freedom" from moods can be practiced through conscious awareness of one's own mood and the mood of others, exploration of what assessments trigger unproductive moods and the standards that give rise to those assessments, changing the standards that give rise to assessments that trigger unproductive moods, and actively cultivating productive moods.

\section{RELEVANCE OF LANGUAGE ACTION AND MOODS}

Projects are organizations. They are groups of people assembled to take action towards accomplishing a common goal. Skilful conversation and language informed by Flores' speech acts strengthens communication and thereby facilitates action.

Proper understanding and use of the speech acts is critical to projects. Confusing speech results in unwanted, improper or insufficient action, such as when a request is confused with an order ("Will you finish foundation concrete this week?"), or a declaration is confused with a request ("We are not on schedule. I think we need to bring more people."), or when a promise is unfulfilled. These miscommunications result in poor planning and an environment of unreliable workflow. Lean construction principals and The Last Planner System seek to reverse this trend. 
The Last Planner System, a commitment-based production process control system, brings an awareness of the conversations needed to make commitments, concentrating on the speech acts of offer, request and promise. Any implementation of the speech acts is an improvement over traditional project coordination conversation, but further emphasis on the remaining speech acts, assessment and assertion, would be an even greater improvement. Additionally, formally recognizing the role of productive and unproductive moods is necessary to coordinate action with optimal skill and efficacy.

The speech acts and the role of moods are in play in conversations whether or not the team acknowledges their presence. For example, a simple commitment such as a promise to finish the foundation concrete requires the use of the speech act "promise." Similarly, other conversations, such as requesting work from another subcontractor or requesting concrete from the concrete provider, require the use of the "request" speech act. There are several identifiable elements at play during conversation; for instance, an effective promise involves a speaker, a listener, a specified time for fulfilment, conditions of satisfaction, a background of obviousness, future action to be performed by the speaker, the performer's ability to fulfil their promise, sincerity, shared concerns, and possibilities for the future (Flores, 2012). Alternatively, an effective request requires the performer and listener to make assessments and assertions in preparation for a promise, such as the declaration by the owner that the job must be competed under a certain cost (declaration), that the drawings indicate a concrete additive is required (assertion), the number of concrete trucks needed (assessment), or the quality of the rebar installation (assessment).Moreover, conversational interactions benefit from the understanding that moods are always present and provide context for communication through feelings such as distrust as in "I do (or do not) trust the subcontractor", or irritability as in "the foreman angered me so I'm not listening to them anymore". The inherent nature of speech acts and moods suggests that consciously recognizing their effectiveness creates an opportunity to improve conversations.

Other studies have also explored how moods can be influenced, are contagious, and impact event outcomes. The clinical study (Kadom et al., 2017) measured the impact of improved mood on adverse procedural outcomes during image-guided interventions. The authors noted "The procedure room is a two-way street in which the patient can affect the healthcare professional and vice versa" suggesting that negative moods are contagious. The team found that improving patient's mood from negative to positive reduced the occurrence of adverse procedural outcomes. Interestingly, once in the positive mood range, further positive improvement of mood did not show additional reduction in adverse procedural outcomes. One of the authors recommended training for procedureroom workers in coping strategies as well as in techniques to help patients reverse negative thought processes.

A functional MRI study of the human brain, in which participants were asked to make positive facial expressions during the scan, demonstrated how moods can be influenced (Kohnet al. 2013). Participants' moods were recorded before and after making positive facial expressions. Participants with elevated mood activated the areas in yellow in their brains; (Fig. 1.) the more positive the mood, the stronger the activation of these areas. The results of this study clearly indicated that making positive facial expressions 
(inductions) for one-minute intervals in between breaks (baseline) altered brain function in a positive and measurable way among participants. To put it plainly, the act of smiling actually made them happy. There is clearly a reciprocal relationship between moods and facial expression: not only does mood inform expression, but facial expression also affects mood, even when artificially produced.

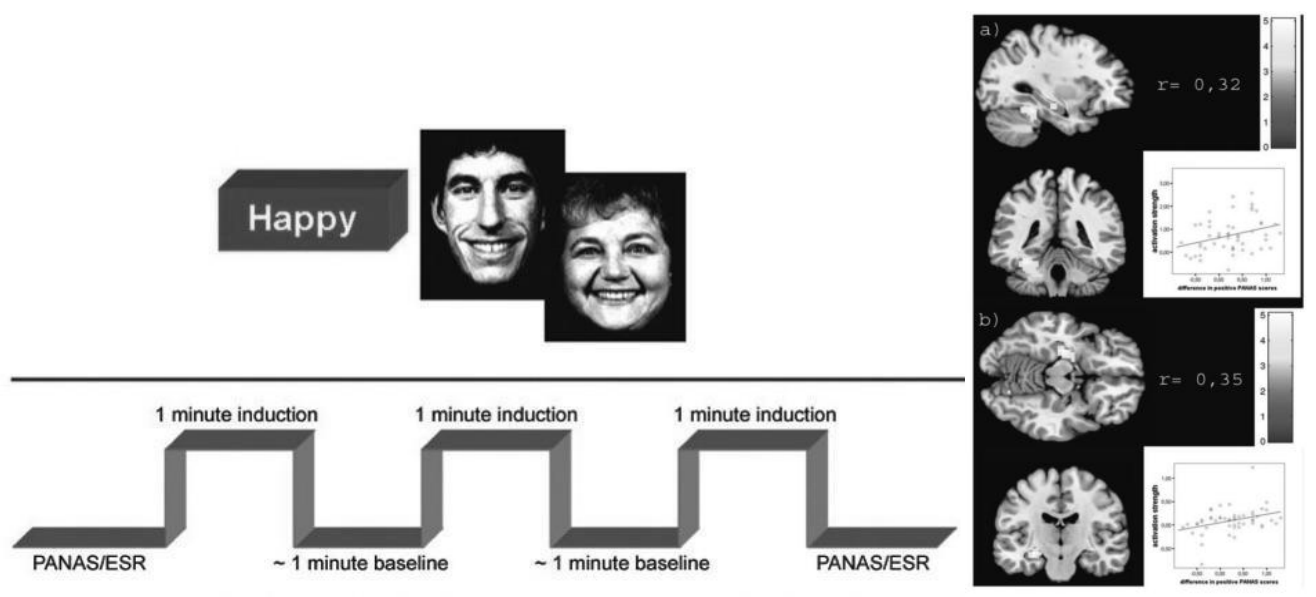

Figure 1: In the upper half of the figure two sample images of the facial stimuli used for support in the mood induction are displayed. On the right is a functional MRI showing the activity in the brain as a result of the positive stimuli. (Kohn, N. et al 2013)

\section{SUMMARY OF PREVIOUS STUDIES}

A literature study, primarily of IGLC papers was conducted in which the terms "language action," "linguistic action," and related terms were searched. Each paper was independently searched for the terms at the top of the table and their occurrence in the papers recorded. 
Table 2: Literature Review

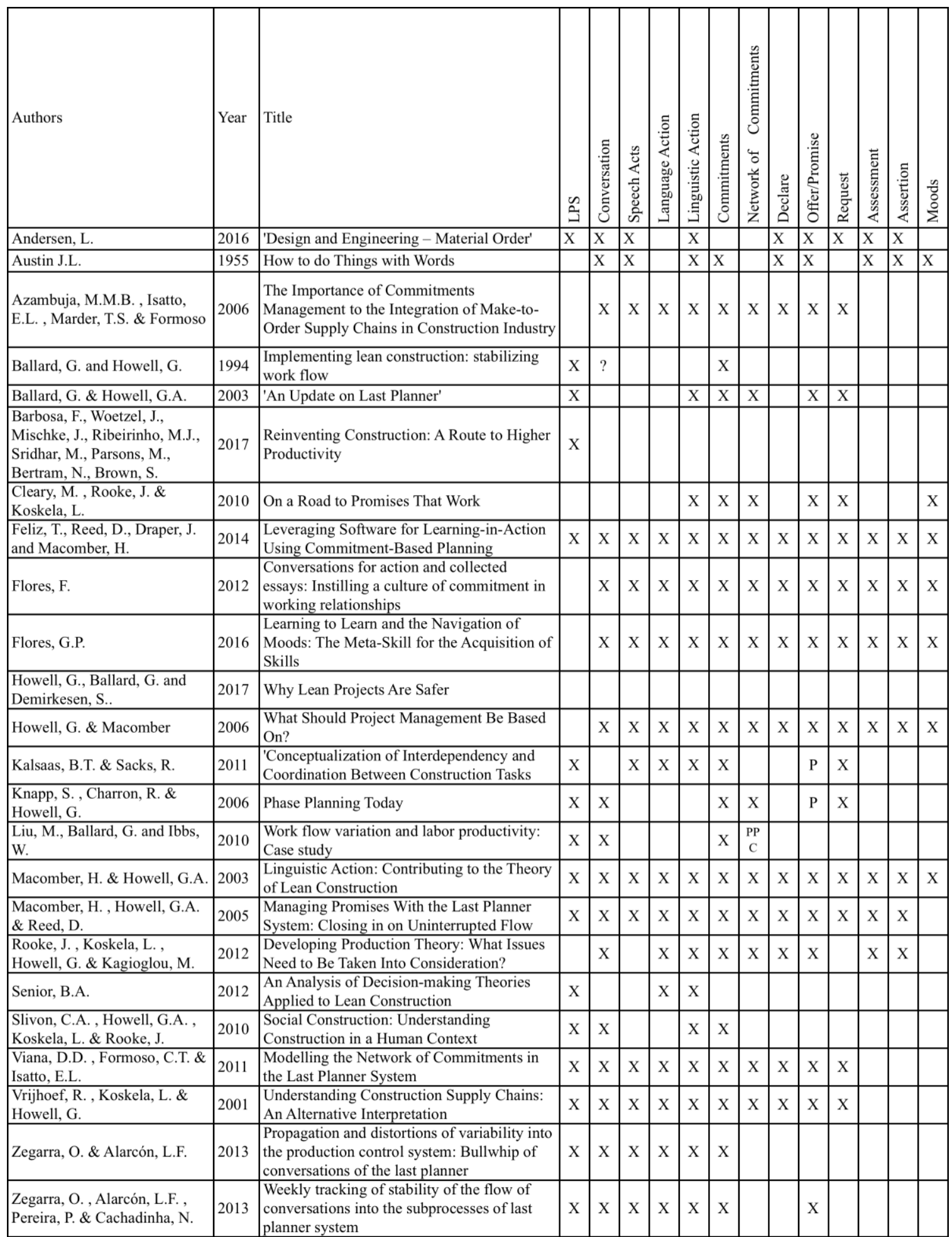


As can be seen from the summary of previous studies (Table 2), the lean construction community has discussed connecting the linguistic action perspective to lean methods and project performance. However, less has been said about the connection between mood, learning behaviour and improved project performance. While the connection between improved project performance and communication makes intuitive sense, design and construction teams do not explicitly talk about how language is used on projects or how the project team's mood affects their work. There are numerous examples of conversations that are detrimental to the progress of the project, and regular project participants can easily identify with them, but standard methods of recognizing and changing language habits on projects have not been developed or even seriously considered.

\section{CONCLUSIONS}

The design and construction industry has not yet solved its low rate of increase in productivity. There have been productivity improvement approaches outlined, and while the components of their observations are sound, they address extrinsic obstacles to progress rather than investigating interpersonal dynamics that can and should be optimized. Changing the norms of communication, the use of language and the recognition of moods on projects could revitalize the construction industry by increasing more than just productivity but also overall project performance and drastically improving the workplace culture. How project managers and team members use or don't use language in the working environment directly impacts their ability to establish an environment of positive moods conducive to increased performance. The efficiency and follow-through of project tasks, and good intentions on the part of communicators alone is not enough to prevent misunderstandings - particularly when teams lack the sensibilities to differentiate between speech acts and a systematic method for approaching conversations. Based on a review of relevant texts that emphasize the connections between productivity, language, and mood, evidence indicates that shifting to a positive mood is synonymous with a shifting to a mood of high productivity and high performance. More experimentation and research should be done to explore how these observations can improve systems and methods in the construction industry and how to effectively shift teams toward high performance by steering them into positive moods.

\section{ACKNOWLEDGMENTS}

We would like to acknowledge the editing contribution of Ava Wallace.

\section{REFERENCES}

Andersen, L. (2016). "Design and Engineering - Material Order" In:, 24th Annual Conference of the International Group for Lean Construction. Boston, USA, 20-22 Jul 2016.

Austin, J.L., (1975). How to do things with words. Oxford university press.

Azambuja, M.M.B., Isatto, E.L. , Marder, T.S. andFormoso, C.T. (2006). "The Importance of Commitments Management to the Integration of Make-to- Order 
Supply Chains in Construction Industry" In:, 14th Annual Conference of the International Group for Lean Construction. Santiago, Chile, 1-. pp 609-623.

Ballard, G. and Howell, G., (1994). Implementing lean construction: stabilizing work flow. Lean construction, pp.101-110.

Ballard, G. \& Howell, G.A. (2003). "An Update on Last Planner" In:,11th Annual Conference of the International Group for Lean Construction. Virginia, USA.

Barbosa, F., Woetzel, J., Mischke, J., Ribeirinho, M.J., Sridhar, M., Parsons, M., Bertram, N., and Brown, S. (2017). "Reinventing Construction: A Route to Higher Productivity". Mckinsey Global Institute, Research. Insight. Impact. Feb 2017.

Cleary, M., Rooke, J. andKoskela, L. (2010), "On a Road to Promises That Work" In:, Walsh, K. \& Alves, T., 18th Annual Conference of the International Group for Lean Construction. Haifa, Israel, 14-16 Jul 2010. pp 366-385.

Edmondson, A. (1999). "Psychological Safety and Learning Behaviour in Work Teams"Administrative Science Quarterly, 44 (2), 350-383.

Feliz, T., Reed, D., Draper, J. and Macomber, H., (2014).“Leveraging Software for Learning-in-Action Using Commitment-Based Planning” Oslo, Norway: 22nd Annual Conference of the International Group for Lean Construction.

Flores, F., (2012). Conversations for action and collected essays: Instilling a culture of commitment in working relationships. CreateSpace Independent Publishing Platform.

Flores, G.P. (2016). Learning to Learn and the Navigation of Moods: The Meta-Skill for the Acquisition of Skills. Pluralistic Networks Publishing.

Folkestad, J. and Howell, G. (2007). "Do Projects Have Horsemen?: Investigating the Warning Signs of Unreliable Commitments" In:, Pasquire, C.L, C.L. \&Tzortzopoulos, P., 15th Annual Conference of the International Group for Lean Construction. East Lansing, Michigan, USA, 18-20 Jul 2007. pp 423-430.

Howell, G., Ballard, G. and Demirkesen, S., (2017)“Why Lean Projects Are Safer" In 25th Annual Conference of the International Group for Lean Construction. Heraklion, Greece.pp. 9-12.

Howell, G. and Macomber, H. (2006). "What Should Project Management Be Based On?" In:, 14th Annual Conference of the International Group for Lean Construction. Santiago, Chile. pp. 41-50.

Kalsaas, B.T. \& Sacks, R. (2011). "Conceptualization of Interdependency and Coordination Between Construction Tasks" In:, Rooke, J. \& Dave, B., 19th Annual Conference of the International Group for Lean Construction. Lima, Peru. pp. 13-15.

Kadom, N., Nguyen, X.V., Jensen, M.P. and Lang, E.V., (2017). "Effects of Patients' Affect on Adverse Procedural Events during Image-Guided Interventions."Journal of Vascular and Interventional Radiology, 28(12), pp.1732-1738.

Knapp, S., Charron, R. and Howell, G. (2006), "Phase Planning Today" In:,14th Annual Conference of the International Group for Lean Construction. Santiago, Chile. pp 431-441.

Kohn, N., Falkenberg, I., Kellermann, T., Eickhoff, S.B., Gur, R.C. and Habel, U. (2013)."Neural correlates of effective and ineffective mood induction."Social cognitive and affective neuroscience, 9(6), pp.864-872. 
Liu, M., Ballard, G. and Ibbs, W.(2010)."Work flow variation and labor productivity: Casestudy." Journal of management in engineering, 27(4), pp.236-242.

Macomber, H. \& Howell, G.A. (2003). "Linguistic Action: Contributing to the Theory of Lean Construction" In:,11th Annual Conference of the International Group for Lean Construction. Virginia, USA.

Macomber, H., Howell, G.A. \& Reed, D. (2005) "Managing Promises With the Last Planner System: Closing in on Uninterrupted Flow" In:,13th Annual Conference of the International Group for Lean Construction. Sydney, Australia, 19-21 Jul 2005. pp 13-18.

Rooke, J., Koskela, L., Howell, G. \&Kagioglou, M. (2012) "Developing Production Theory: What Issues Need To Be Taken Into Consideration?" In:,Tommelein, I.D. \&Pasquire, C.L., 20th Annual Conference of the International Group for Lean Construction.San Diego, USA. pp.18-20.

Searle, J.R., (1969). Speech acts: An essay in the philosophy of language (Vol. 626). Cambridge university press.

Senior, B.A. (2012). "An Analysis of Decision-Making Theories Applied to Lean Construction" In:,Tommelein, I.D. \&Pasquire, C.L., 20th Annual Conference of the International Group for Lean Construction. San Diego, USA. pp. 18-20.

Slivon, C.A., Howell, G.A., Koskela, L. and Rooke, J. (2010). "Social Construction: Understanding Construction in a Human Context" In:, Walsh, K. \& Alves, T., 18th Annual Conference of the International Group for Lean Construction. Haifa, Israel, 14-16 Jul 2010. pp 2-11.

Viana, D.D., Formoso, C.T. \&Isatto, E.L. (2011). "Modelling the Network of Commitments in the Last Planner System" In:, Rooke, J. \& Dave, B., 19th Annual Conference of the International Group for Lean Construction. Lima, Peru. pp. 13-15.

Vrijhoef, R., Koskela, L. \& Howell, G. (2001). "Understanding Construction Supply Chains: An Alternative Interpretation" In:, Ballard, G. \& Chua, D., 9th Annual Conference of the International Group for Lean Construction. Singapore, Singapore.

Zegarra, O. \&Alarcón, L.F. (2013). "Propagation and distortions of variability into the production control system: Bullwhip of conversations of the last planner" In:,Formoso, C.T. \& Tzortzopoulos, P., 21th Annual Conference of the International Group for Lean Construction. Fortaleza, Brazil. pp 589-598.

Zegarra, O., Alarcón, L.F., Pereira, P. \& Cachadinha, N. (2013) "Weekly tracking of stability of the flow of conversations into the subprocesses of last planner system" In:,Formoso, C.T. \&Tzortzopoulos, P., 21th Annual Conference of the International Group for Lean Construction. Fortaleza, Brazil, 31-2 Aug 2013. pp. 629-638. 